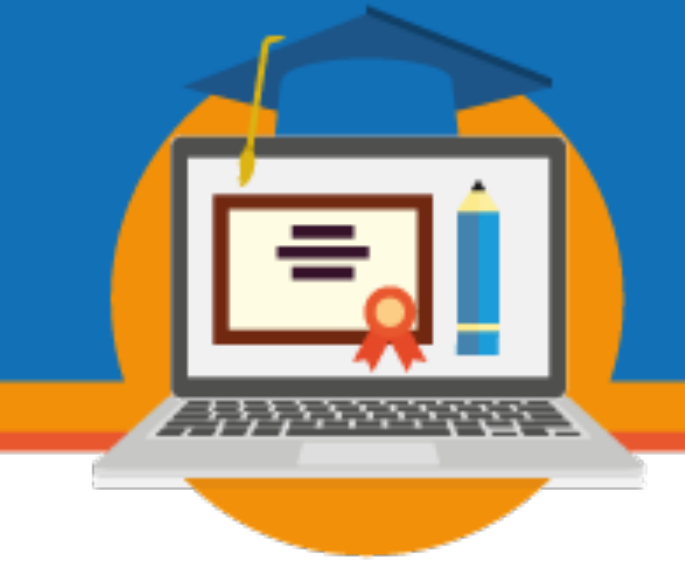

\title{
O USO DE TIC NO EAD: WEB'S AO VIVO COMO PROPULSOR DA INTERAÇÃO ENTRE DISCENTES E DOCENTE
}

\author{
Alexsandro Barreto Gois \\ Centro Universitário de Brasília - UniCEUB \\ Universidade de Brasília - UnB \\ prof.alexsandrobarreto@gmail.com
}

\author{
Fernanda Maria Furst Signori \\ Secretaria de Educação do Distrito Federal - GDF \\ fernandasignori@bol.com.br
}

Eixo 3: Tecnologias, mídias e processos inovadores na EaD

\begin{abstract}
Resumo: O presente trabalho tem como objetivo tratar sobre o uso de tecnologias de informação e comunicação no contexto do ensino a distância, fomentando a inovação, a qualidade e a relação entre discente e docente no processo de ensino-aprendizagem. $\mathrm{O}$ uso de tecnologias de informação e comunicação no ensino a distância promove uma maior interação entre os agentes do processo de ensino-aprendizagem. Dessa forma, discentes e docente estão mais próximos nesse processo, percebendo-se que o ensino a distância não precisa ser distante, sentindo-se mais próximos com o uso de tecnologias no EaD, por exemplo, com o uso de web's ao vivo que propulsionam a interação entre os partícipes.
\end{abstract}

Palavras-chave: Ensino a Distância. TIC. Web’s ao Vivo.

\section{Introdução}

O maior desafio que se encontra no ensino a distância, na atualidade, é como reter os estudantes durante o processo de ensino-aprendizagem. Assim, a dificuldade é encontrar o instrumento que melhor auxilie nesse processo. É nesse contexto que construímos o objetivo desta pesquisa, que é tratar sobre o uso de tecnologias inovadoras no contexto do ensino a distância, fomentando qualidade, inovação e maior interação entre discente e docente no processo de ensino-aprendizagem. 
Segundo Castells (2003), o surgimento de novas tecnologias e a maior interação que elas proporcionam no contexto atual são necessários a inclusão no nosso cotidiano, como estratégia de inovação e racionalidade na realização de diversas atividades. E no processo de ensino-aprendizagem não é diferente, pois a utilização de tecnologias que fomentem esse processo é imprescindível para acompanhar as mudanças sociais, culturais e tecnológicas que estão inseridas no mundo atual, como afirma Morin (2007). Essa perspectiva de maior utilização de tecnologias também está inserida no ensino a distância.

O ensino superior a distância está em pleno crescimento, comparado ao ensino superior presencial. Nesse sentido, o ensino a distância está cada vez mais em renovação, surgindo desafios a serem superados constantemente, os quais estão centrados na prática pedagógica do professor somado à utilização de tecnologias sustentáveis, de acordo com Carvalho (2013).

O desafio de manter um ensino superior a distância de qualidade e reduzir ao máximo o absenteísmo dos cursos faz com que o processo de ensino-aprendizagem se renove cotidianamente, incluindo tecnologias sustentáveis que conectem os papéis dos discentes e do docente, aproximando-os. Um dos exemplos da utilização dessas tecnologias são as web's ao vivo, como webconferência, webencontro e webrevisão, que fomentam a interação entre discente e docente no ensino a distância, promovendo a aproximação de ambos os atores, tornando esse processo mais instigante.

Ainda, nas web's, utiliza-se o chat, ferramenta que possibilita o diálogo entre aluno e professor em tempo real. Essa interação realizada entre os atores no processo de ensinoaprendizagem, por meio da utilização de tecnologias, é fundamental para fomentar os aspectos de qualidade e de inovação no ensino, da aproximação da relação entre discentes e docente, reduzindo, assim, o absenteísmo dos cursos EaD.

\section{Metodologia}

Quanto aos objetivos da pesquisa, ela é explicativa, pois conecta ideias de forma a tentar explicar as causas e os efeitos de determinado fenômeno. Com esse tipo de pesquisa, tentamos

\section{SEMINÁRIO DE EDUCAÇÃO A DISTÂNCIA}


compreender os efeitos da interação entre os atores envolvidos no processo de ensinoaprendizagem - discentes e docente - no âmbito do ensino a distância, utilizando-se de métodos experimentais e por observação.

Quanto à fonte de pesquisa, as fontes utilizadas foram primárias e secundárias. As primárias compreendem a consulta e utilização de artigos e dissertações. Já as fontes secundárias compreendem a utilização de livros.

Quanto à apresentação dos resultados, a pesquisa é qualitativa, pois expõe a análise de conceitos e ideias adquiridos durante a pesquisa. Quanto ao procedimento de tratamento da pesquisa, utilizou-se de pesquisa bibliográfica e pesquisa de campo. No primeiro, teve como propósito reunir dados em que a pesquisa é baseada. No segundo, objetivou extrair dados e informações diretamente da realidade do objeto de estudo.

\section{Resultados e Discussões}

Os dados obtidos na pesquisa trouxeram percepções quanto à interação entre discentes e docente no processo de ensino-aprendizagem no ensino a distância. Antes de se utilizar de ferramentas de interação entre discentes e docente, percebeu-se que um quantitativo maior de alunos desistia ou não finalizava atividades, com a justificativa de falta de interação entre os atores envolvidos. Após a inclusão de ferramentas de interação ao vivo entre discentes e docente, como webconferência, webencontro e webrevisão, no estilo de "live", percebeu-se que os discentes gostaram de participar dessa atividade e um percentual menor de alunos desistiu ou deixou de finalizar as atividades propostas.

Dessa forma, essas ferramentas de interação ao vivo, como percebido por Carvalho (2013), aumentaram o interesse de participação dos discentes nas diversas atividades de cada disciplina. Considerando que os discentes interagiam com o docente e têm mais um momento em que podem sanar dúvidas com o docente sobre todas as outras atividades e sobre a avaliação presencial. A webconferência tem como propósito a discussão de um tema específico que esteja paralelo à disciplina, com o intuito de enriquecer as discussões dos conteúdos da disciplina. A 


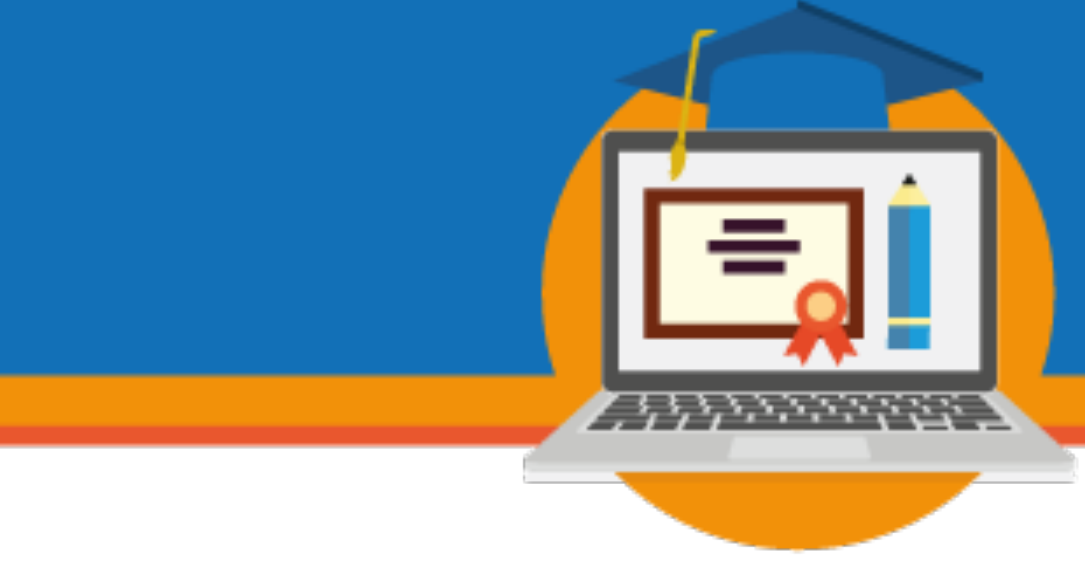

webencontro, com um tempo mais curto, objetiva trazer a discussão de um tema específico e curto vinculado com o cotidiano, que faça conexão com a disciplina. Já a webrevisão, a discussão dos pontos mais importantes da disciplina, para auxiliar na realização da avaliação final.

\section{Considerações Finais}

O processo de ensino-aprendizagem no ensino a distância necessita da utilização de um maior número de ferramentas de interação entre os atores envolvidos - discentes e docente. Nesta pesquisa, percebeu-se que a utilização de ferramenta ao vivo, como webconferência, webencontro e webrevisão, com a interação entre discentes e docente, aumentou o percentual de participação em todas as atividades de cada disciplina e o percentual de conclusão das disciplinas, reduzindo-se, assim, o absenteísmo e desistências dos discentes.

Esta pesquisa confirma a percepção obtida por Carvalho (2013) em sua pesquisa de dissertação, em que se utiliza da ferramenta de "webquest" para a interação entre discentes e docente no processo de ensino-aprendizagem, fomentando a participação dos discentes no processo de aprendizagem. 


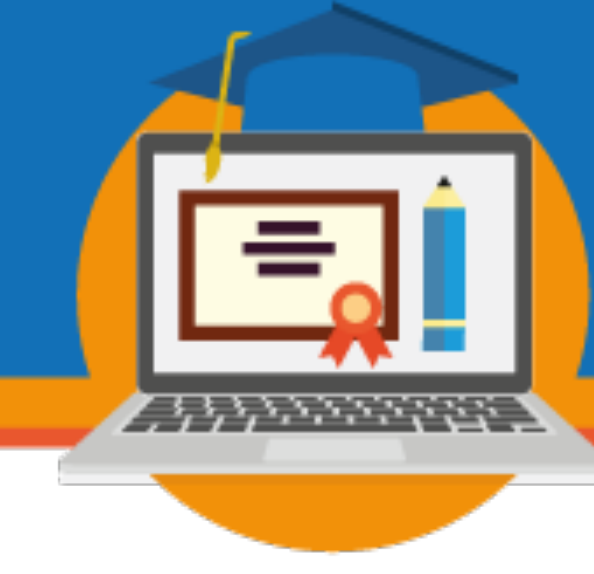

\section{Referências}

CARVALHO, Ártemis Barreto. Webquest no facebook: uma experiência no curso técnico em guia de turismo do IFS usando uma rede social como ambiente de ensinoaprendizagem on-line. 2013. Sergipe, Faculdade de Educação da UFS. Dissertação de Mestrado.

CASTELLS, Manuel. A galáxia da internet: reflexões sobre a internet, os negócios e a sociedade. Rio de Janeiro: Zahar, 2003.

MORIN, José Manuel. A educação que desejamos: novos desafios e como chegar lá. Campinas: Papirus, 2007. 